\title{
Resiliência, escala e participação em governos de direita: uma análise da Consulta Popular, no Rio Grande do Sul (1998-2018) ${ }^{1}$
}

Igor Ferraz da Fonseca² (i)

O cenário em torno das instituições participativas brasileiras é marcado por certa estagnação, tendo em vista vínculos históricos com partidos de esquerda. $\mathrm{Na}$ conjuntura posterior às eleições de 2018, faz-se necessário voltar o olhar para experiências ativas em governos conservadores. Nessa linha, este artigo analisa uma experiência supralocal institucionalizada por um governo de direita e que possui mais de 20 anos de história: a Consulta Popular, no Rio Grande do Sul. O referencial teórico discute o salto de escala e a institucionalização da participação, e a metodologia utilizada foi qualitativa, com ênfase na técnica de rastreamento de processos (process tracing). Os resultados mostram que o aumento de escala foi insuficiente para garantir uma transformação ampla do sistema político. No entanto, a Consulta apresenta uma forma inovadora de promover a participação e a deliberação em escala supralocal, a partir da perspectiva da governança suficientemente boa. Já a institucionalização foi fundamental para explicar sua resiliência em relação às mudanças de governo. Por fim, o caso aponta que, se a instituição participativa mostra resultados em termos de eficiência na gestão pública e não tem a ambição de alterar o status quo preestabelecido, a participação pode ser tolerada e incentivada em governos de direita.

Palavras-chave: salto de escala; institucionalização; Rio Grande do Sul; Consulta Popular; sistemas deliberativos

Introdução ${ }^{3,4}$

O cenário em torno das instituições participativas (IPs) brasileiras é atualmente marcado por certa estagnação (e mesmo retrocessos). Após décadas de difusão, os últimos anos assinalaram questionamentos sobre a efetividade de tais instrumentos (Pires, 2011), polêmicas em torno de incorporação de IPs no âmbito do governo - como no caso dos conflitos em torno do Decreto 8.243/2014, que instituiu o Sistema Nacional de Participação

\footnotetext{
${ }^{1}$ Este artigo é fruto de doutorado realizado na Universidade de Coimbra. A pesquisa contou com o apoio do CNPq, Conselho Nacional de Desenvolvimento Científico e Tecnológico, e foi elaborada no âmbito do Instituto da Democracia e da Democratização da Comunicação.

2 Instituto de Pesquisa Econômica Aplicada (Ipea), Brasília (DF), Brasil. E-mail: <igorffonseca@gmail.com>.

3 Deixo aqui agradecimentos aos meus orientadores Giovanni Allegretti e Leonardo Avritzer. Os agradecimentos são estendidos aos pareceristas anônimos da Opinião Pública.

40 presente artigo contém alguns trechos que também estão presentes em Fonseca (2019).
} 
Social $^{5}$ (Alencar e Coelho, 2014) - e mudanças de governo e de projeto político em nível nacional que trouxeram consigo uma ênfase menor em processos participativos.

No Brasil, os mecanismos participativos foram recorrentemente associados aos governos de esquerda, em especial ao Partido dos Trabalhadores (PT). Isso, obviamente, apresenta um desafio às IPs, que podem enfrentar dificuldades em governos com orientação política diferente. No entanto, há casos em que a participação social prospera em governos de direita. No cenário político brasileiro posterior às eleições de 2018 , faz-se necessário voltar o olhar para experiências participativas ativas em governos conservadores. Compreender quais são as principais características (potencialidades e limites) desses processos, bem como analisar a resiliência de mecanismos participativos a mudanças significativas de orientação governamental, parece ser um caminho necessário ao campo de estudos nacionais sobre democracia e participação.

Este artigo tenta dar maior concretude a esse debate, com base na análise de um processo participativo singular, criado por um governo de centro-direita e que possui mais de 20 anos de história, tendo sobrevivido a seis mudanças governamentais, a partidos políticos e a orientações ideológicas distintas. Trata-se da Consulta Popular (CP), institucionalizada em nível estadual, no Rio Grande do Sul (RS), Brasil.

Para explicar a resiliência, as potencialidades e os limites de tal IP, é necessário enfatizar duas de suas principais características: trata-se de uma iniciativa supralocal e institucionalizada. A base teórica deste artigo enfatizará o salto de escala e a institucionalização da participação social.

Uma das principais justificativas para promoção de iniciativas supralocais vem da constatação de que as experiências em nível local sofrem grande influência do contexto social e político de maior escala, o que muitas vezes tem impacto sobre sua efetividade e perenidade. Sem um vínculo direto com processos políticos mais amplos, as deliberações oriundas de fóruns participativos e deliberativos podem não ser traduzidas em ações concretas, pois instâncias locais muitas vezes carecem de prerrogativas e capacidades para incidir sobre políticas públicas em diversos níveis de governo.

A importância do salto de escala (scaling-up) está intimamente vinculada ao processo de institucionalização da participação. Por grau de institucionalização, entendese a incorporação dos mecanismos no âmbito do Estado por meio de um vínculo direto entre os resultados da instância participativa e o processo decisório. A institucionalização tem como objetivo garantir certa perenidade aos mecanismos, assim como formalizar sua integração ao processo de policy making.

Em contrapartida, críticos da institucionalização apontam que tal movimento pode reduzir a flexibilidade e o potencial de inovação, que são comumente associados às experiências não institucionalizadas. Se a formalização pode induzir uma maior legitimidade das instâncias participativas dentro do Estado, argumentos críticos enfatizam

5 O Decreto 8.243/2014 foi revogado pelo Decreto 9.759/2019, em seu artigo $10^{\circ}$. Esse decreto também estabelece novas regras e busca extinguir uma série de colegiados vinculados ao governo federal, denotando um momento difícil para mecanismos participativos em nível federal no Brasil. 
que a institucionalização pode gerar uma nova crise de legitimidade, dessa vez por parte de atores da sociedade civil. A percepção é de que a participação promovida pelo Estado de cima para baixo (top-down) - acabe por retirar autonomia da sociedade civil, reduzindo o potencial transformador da democracia participativa.

Este artigo teve como referência metodológica a tradição de pesquisa qualitativa em ciências sociais, tanto na escolha do caso quanto nos procedimentos de análise. Adotou um conjunto de técnicas, utilizadas de forma complementar, a saber: os estudos de caso (Yin, 2014) e a técnica de rastreamento de processos - process tracing (Collier, 2011; Mahoney, 2012).

O process tracing reconstruiu a trajetória da CP entre 1998 e 2018, identificando fatores que explicam mudanças na trajetória da experiência estudada. A pesquisa identificou que os períodos de mudanças de governo são momentos-chave para explicar tanto a resiliência da CP quanto suas mudanças de ênfase e de orientação ao longo do tempo. Posteriormente a cada mudança governamental, foram identificados ciclos de "ativismo político" dos Conselhos Regionais de Desenvolvimento (Coredes), atores centrais na implementação da CP. Nesses ciclos de ativismo, os Coredes iniciam períodos de negociação com o novo governo eleito, pressionando pela manutenção do processo formalizado em lei e realizando concessões no que tange à metodologia dos processos e suas principais ênfases (inclusão política e quantidade de participantes para governos de esquerda; eficiência administrativa para governos de direita).

A pesquisa de campo foi realizada entre outubro de 2015 e julho de 2017 e contemplou 25 entrevistas semiestruturadas ${ }^{6}$, coleta de dados bibliográficos e documentais e o acompanhamento in loco do XVIII Encontro Anual de Avaliação e Planejamento dos Coredes, realizado nos dias 18 e 19 de novembro de 2015. A evolução da CP foi monitorada à distância até o final do ano de 2018. Neste artigo, optou-se por não citar diretamente os entrevistados para não suscitar sensibilidades políticas.

Os resultados mostram que, por um lado, o aumento de escala foi insuficiente para garantir uma maior influência da IP na transformação ampla do sistema político gaúcho. Os impactos da CP estiveram limitados às políticas estaduais de desenvolvimento regional, não afetando de forma direta outras áreas de política pública. Apesar de contar com o apoio de diversos governos municipais, a CP também não teve influência na democratização e no aumento de transparência de administrações locais. Por outro lado, a Consulta Popular apresentou uma forma inovadora de atuação em escala supralocal, ao combinar formas participativas, representativas e eleitorais em um único desenho

\footnotetext{
6 Entre os entrevistados estão contempladas pessoas que atuaram na implementação da CP em suas diferentes fases. Quatro entrevistados foram agrupados na categoria "atores políticos", contemplando governadores e secretários estaduais de diferentes gestões. Catorze entrevistados foram incluídos na categoria "burocratas", contemplando servidores e ex-servidores públicos (tais como diretores e coordenadores de área). Dez dos "burocratas" atuaram no governo estadual, três em governos locais do RS e um no governo federal. Cinco entrevistados foram incluídos na categoria "membros de Coredes", representando cinco diferentes Coredes. Por fim, foram entrevistados dois membros da sociedade civil estadual, que eram também conselheiros no Conselho Estadual dos Direitos das Pessoas com Deficiência e no Conselho de Segurança Alimentar e Nutricional Sustentável do RS.
} 
institucional.

No que diz respeito à resiliência, a CP apresentou resultados ambíguos. Verificouse que a formalização por meio de leis contribuiu incisivamente para a perenidade dela, ampliando sua resistência às mudanças de governo. Ademais, as formas adotadas de institucionalização permitiram certa flexibilidade aos atos jurídicos e aos modelos de gestão da $\mathrm{CP}$, não justificando os receios dos críticos em relação à redução da flexibilidade e à cooptação das instituições participativas por atores estatais. No entanto, apesar de necessária para sua manutenção, a institucionalização formal não garantiu, por si só, efetividade. Coalizões de defesa em torno da CP foram fundamentais para mobilizar politicamente as leis para que estas garantissem o seu sustento. Além disso, foi notado que resiliência não implica maior influência da IP no núcleo central de governo. Em um contexto de Estados fragmentados e marcados por disputa entre projetos políticos, a institucionalização da iniciativa gaúcha foi consolidada às margens do sistema político.

Por fim, com relação à orientação política do governo, percebe-se que a CP conseguiu superar a identificação com determinados partidos e orientações políticas. Se é verdade que cada governo estadual (de direita ou de esquerda) enfatizou aspectos do processo mais alinhados às suas ideologias e visões de mundo, a discussão central foi além da polarização entre haver ou não mecanismos de participação, concentrando-se no debate sobre qual modelo participativo deveria ser adotado.

O artigo está dividido em seis seções, sendo a primeira esta Introdução. A segunda seção, "Das vertentes puras às perspectivas híbridas: escala e institucionalização nas teorias democráticas", discute os dilemas de escala e as teorias em torno da institucionalização da participação. A terceira, "A Consulta Popular: um processo participativo institucionalizado em nível supralocal", apresenta brevemente a Consulta Popular, a partir de seus objetivos, atores envolvidos e desenho institucional. A quarta, "Consulta Popular: uma trajetória de 20 anos", realiza uma reconstrução da trajetória da CP enquanto política pública, a partir dos referenciais metodológicos adotados. A quinta seção, "Discussão: inovações institucionais e resiliência da Consulta Popular", reflete sobre os principais pontos inovadores do caso gaúcho. A discussão estrutura-se em três dimensões centrais. A subseção "Combinando participação e processos eleitorais em nível supralocal" trata da relação entre escala e participação. A subseção "Resiliência e participação: o círculo virtuoso entre os Coredes e a institucionalização" aborda a resiliência da CP às mudanças de governo. A análise das características e dos resultados da CP em governos de centro-direita e centro-esquerda é apresentada na subseção "Eficiência ou inclusão? A Consulta Popular em governos de direita e de esquerda". Por fim, a seção "Considerações finais" resume as principais conclusões do artigo, a partir das três dimensões elencadas. 


\section{Das vertentes puras às perspectivas híbridas: escala e institucionalização nas teorias democráticas}

A base teórica em torno da qual este artigo está estruturado enfatiza um movimento em curso na teoria e na prática de experiências relacionadas às novas formas de participação e deliberação. Tal movimento é marcado pelo significativo descolamento entre as experiências empíricas e a teorização sobre estas.

Após algumas décadas de multiplicação de experiências em pequenas escalas, as instituições participativas e deliberativas ganham terreno e começam a atingir contextos complexos, em escala supralocal. O salto de escala, por um lado, responde a dinâmicas específicas de cada contexto e a uma tendência de replicar, em outras escalas, modelos que se tornaram relativamente comuns e foram considerados boas práticas em escala local, no âmbito da difusão de uma agenda de boa governança (Grindle, 2004, 2007; Santiso, 2001); por outro, também busca minorar um problema de efetividade das instituições locais: ao enfatizar apenas a microescala, muitas experiências inspiradas pelo ideal participativo e deliberativo acabam tendo pouca influência em decisões políticas estruturantes, que geralmente são tomadas em escalas superiores (Chambers, 2009; Goodin e Dryzek, 2006; Hendriks, 2006; Mansbridge et al., 2012).

Nas teorias da democracia, a questão da escala foi justificativa central para que teóricos que defendiam modelos centrados na representação afirmassem que, em sociedades modernas e complexas, a participação social e a cidadania ativa não podiam ir além da pequena escala. Segundo teóricos como Schumpeter (1961), Dahl (1998), Dahl e Tufte (1973) e Bobbio (1997), em sociedades grandes, o cidadão teria seu papel reduzido àquele de formação de governos, em que a participação política assumiria formas controladas e esporádicas, centradas nos raros momentos eleitorais. A ampliação da complexidade seria um efeito direto do aumento de escala, levando a um quadro em que o peso dos conhecimentos técnicos implicaria a centralidade do especialista - em detrimento do cidadão comum - na tomada de decisões (Bobbio, 1997).

Ao avaliar o modelo representativo hegemônico como símbolo de um esvaziamento democrático nas sociedades modernas, as vertentes da democracia participativa (ver, por exemplo, Barber, 2003; Pateman, 1970) e da democracia deliberativa (ver, por exemplo, Calhoun, 1996; Cohen, 1989; Fishkin, 2009; Habermas, 1992) propõem o retorno da participação cívica ao centro do processo político, abrindo espaço para fóruns e experiências com maior intensidade democrática.

O grande problema é que, em linha com a multiplicação de pequenos fóruns participativos e deliberativos que ganharam terreno em nível internacional a partir da última década do século XX, as vertentes "puras" da democracia participativa e da democracia deliberativa - por razões conjunturais e por escolhas metodológicas - deram origem as suas teorias tendo como referencial a escala local. O nível local foi romantizado, obscurecendo relações de poder que se reproduzem em pequena escala, e visto como lócus ideal para a manifestação dos princípios deliberativos e participativos (Cleaver, 2005; 
Cooke e Kothari, 2001; Mohan e Stokke, 2000). Esse movimento fez com que as vertentes "puras" deixassem na tangente de seus modelos os dilemas da escala. Nem autores centrais nas correntes - como Jürgen Habermas - conseguiram questionar tais dilemas, ao confirmar que a escala continua sendo um limite para um amplo processo de democratização (Faria, 2007).

O efeito colateral da ênfase dada pelas vertentes "puras" em pequenos fóruns foi negligenciar estruturas em maior escala (Chambers, 2009; Goodin e Dryzek, 2006). Assim sendo, este artigo argumenta que os referenciais da democracia participativa e da democracia deliberativa são insuficientes para analisar experiências supralocais de participação e de deliberação. É inadequado construir inovações democráticas em nível supralocal com base em modelos teóricos orientados predominantemente para a escala local.

A análise das inovações democráticas em grande escala ganhou um novo impulso a partir de evoluções nas teorias "puras". As novas correntes são marcadas por um hibridismo entre as vertentes representativa, participativa e deliberativa, advogando por maior fluidez e intercâmbio entre as abordagens. A partir do reconhecimento de que cada vertente isolada é insuficiente - e estéril do ponto de vista analítico - para compreender a evolução em torno da multiplicação e implementação das experiências democráticas, as vertentes híbridas apostam em abordagens menos idealistas, prometendo um novo olhar sobre as escalas.

Neste artigo, destacam-se duas vertentes híbridas: a vertente participativa "do sul" e a corrente que defende a implementação e a análise de sistemas deliberativos. A vertente participativa "do sul" é peculiar porque tem origem na teorização a partir de experiências participativas empíricas que tiveram lugar em países periféricos, notadamente na América Latina, nas últimas décadas do século XX. A sua ênfase maior em processos empíricos levou ao reconhecimento de que, na prática, é insuficiente e limitada a filiação a uma única corrente teórica. Para a compreensão dos processos reais de implementação de políticas, é fundamental mesclar elementos das abordagens participativa, deliberativa e representativa.

As experiências participativas "do sul" apresentam características inovadoras, tais como: a) a promoção de formas de participação e deliberação impulsionadas pelo diálogo e pela articulação entre atores estatais e não estatais, em um contexto marcado pelo trânsito de indivíduos que circulam entre os polos da administração pública e da sociedade civil (Abers, Serafim e Tatagiba, 2014; Abers e Von Bülow, 2011; Avritzer, 2002; Dagnino, 2002; Dagnino, Olvera e Panfichi, 2006; Marques, 2006; Silva e Oliveira, 2011); b) uma ênfase na inclusão de grupos historicamente excluídos do processo político, na busca por justiça social e por redução das desigualdades (Dagnino, 2002; Santos e Avritzer, 2002); e c) uma articulação entre formas de representação e de participação direta no interior de fóruns participativos e deliberativos (Almeida, 2013; Avritzer, 2007; Lavalle, Houtzager e Castello, 2006; Lüchmann, 2007; Souza, Lima e Teixeira, 2012). 
Assim sendo, a vertente híbrida "do sul" permite abordar de forma mais efetiva o salto de escala, a partir da combinação de formas de representação e de participação e, sobretudo, dá um passo além na defesa das formas institucionalizadas, pois aponta o potencial que as novas instituições têm de democratizar o Estado, ampliando suas capacidades (Abers e Keck, 2008; Pires e Vaz, 2012; Santos, 1999).

Outra vertente híbrida explorada neste artigo trata dos sistemas deliberativos. 0 descolamento entre a teoria e a prática de fóruns deliberativos e participativos e a dificuldade em influenciar escolhas e políticas públicas não passaram despercebidos aos teóricos deliberativos. Na busca por corrigir o idealismo excessivo da abordagem deliberativa - amplamente criticada por teóricos participativos (Pateman, 2012) e agonísticos (Mouffe, 1999, 2013; Purcell, 2008) -, a teoria sistêmica reconhece a inevitabilidade e os problemas das experiências empíricas (Chambers, 2003; Goodin e Dryzek, 2006), passando a advogar uma deliberação possível em contraponto ao ideal deliberativo (Bächtiger et al., 2010; Goodin, 2005). Trata-se de uma reformulação teórica em que os elementos vistos como perniciosos para a vertente deliberativa "pura" - tais como o autointeresse e as relações de poder - são revitalizados (Mansbridge, 1999; Mansbridge et al., 2010, 2012).

Além da relativização das condições ideais de deliberação, a teoria sistêmica incorpora de forma direta o problema da escala, até então negligenciado. Ao deslocar o foco dos resultados obtidos por fóruns deliberativos em pequena escala para a resultante deliberativa do sistema, obtida a partir da interação entre diversas instituições e escalas, a vertente sistêmica retoma uma aspiração potencial do campo deliberativo relegada ao segundo plano: a democratização ampla do sistema político (Dryzek, 2016), consubstanciada em uma reação contra um fosso entre os objetivos macro e micro das teorias deliberativas (Hendriks, 2006) e sua tímida presença em termos de impacto político.

Em adição à ênfase na dimensão da escala, que vai além do foco romantizado em nível local, a perspectiva sistêmica enfatiza a revitalização, dentro da vertente deliberativa, da importância da representação política (Dryzek e Niemeyer, 2006; Mansbridge, 2003, 2011; Saward, 2006; Urbinati e Warren, 2008).

A teoria sistêmica tem ganhado força no campo teórico e alguns autores a veem como o marco de uma nova geração de deliberativistas (Elstub, Ercan e Mendonça, 2016). O grande problema é que tal abordagem ainda foi pouco utilizada para analisar experiências concretas, notadamente os processos supralocais, o que faz com que a teoria sistêmica seja marcada por alto grau de generalidade e pouca força empírica (Almeida e Cunha, 2016; Mendonça, 2016).

Dessa forma, para que seja possível compreender o caso da Consulta Popular em sua complexidade, é necessário que tal experiência seja analisada a partir de referenciais teóricos híbridos e, sobretudo, da perspectiva da "deliberação boa o suficiente" (Bächtiger et al., 2010).

O debate sobre institucionalização da participação é antigo, estando presente 
desde as primeiras formulações das correntes participativas (Barber, 2003; Pateman, 1970) e deliberativas (Cohen, 1989). A visão que cada corrente teórica tende a ter sobre as formas institucionalizadas é influenciada pelo papel que cada uma delas atribui ao Estado, aos burocratas e ao conhecimento técnico/especializado.

A vertente da democracia participativa tende a valorizar a autonomia da sociedade civil perante o Estado, visto por alguns teóricos como uma estrutura intrinsecamente autoritária (Barber, 2003). Nessa perspectiva, a tendência é olhar a institucionalização com certa desconfiança, na medida em que a internalização das ferramentas participativas e deliberativas na estrutura estatal aumenta a influência exercida por políticos, técnicos e burocratas. Tal situação poderia desencadear padrões marcados pelo controle dos processos por parte de atores do Estado, com predomínio do discurso dos especialistas, podendo levar à despolitização, além de favorecer um maior engessamento metodológico e uma maior vulnerabilidade às pressões políticas.

Já a vertente da democracia deliberativa tende a enfatizar a complementaridade de saberes técnicos e não técnicos (Calhoun, 1996; Habermas, 1992) e mostra-se mais aberta à presença de atores governamentais na organização e na atuação de processos deliberativos. Assim sendo, abre-se espaço para uma nova geração de burocratas atuando como facilitadores de comunidades participativas (Fischer, 2009).

Apesar de uma diferença entre as abordagens "puras", nenhuma delas questiona a divisão entre Estado e sociedade civil, estabelecida por autores como Cohen e Arato (1994). A complementaridade e o diálogo entre os polos estatais e não estatais podem variar entre as correntes puras, mas o limite entre as categorias continua claro e bem definido.

Ao contrário, as vertentes híbridas vão além na análise da interação entre Estado e sociedade civil, questionando a própria fronteira entre as categorias. Isso é bem claro a partir da vertente participativa "do sul", que enfatiza as fronteiras fluidas entre os atores do Estado e da sociedade civil, a partir de trajetórias individuais de atores que transitam entre os polos estatais e não estatais (Abers, Serafim e Tatagiba, 2014; Abers e Von Bülow, 2011; Avritzer, 2002; Marques, 2006; Silva e Oliveira, 2011).

Tal postura tem muitas afinidades com a definição de Estado como um campo de disputa e como um ente não monolítico. Em tal visão, o Estado seria fragmentado e interpenetrado por fluxos e múltiplas interações entre seus componentes, sendo em si a resultante das disputas por hegemonia em seu interior (Migdal, 2004).

Mais importante que a divisão entre Estado e sociedade civil é a disputa entre projetos políticos e modelos de sociedade (Dagnino, 2002; Dagnino, Olvera e Panfichi, 2006). Os projetos políticos são conjuntos de crenças e ideologias compartilhadas por atores estatais e não estatais que se articulam por meio de redes de políticas públicas (Bonafont, 2004), formando coalizões de defesa em torno de certas políticas (Sabatier e Weible, 2007).

Dessa forma, nas abordagens híbridas, as redes e a conexão entre os atores são 
fundamentais (Abers e Von Bülow, 2011; Marques, 2006; Santos, 1999). Ganha força a ideia de ativismo feito de dentro da estrutura estatal, com a participação ativa de burocratas. A desconstrução e a reformulação do Estado, a partir de sua concepção enquanto campo de disputa, abrem a possibilidade para pensar as instituições participativas e deliberativas, uma vez institucionalizadas, como agentes de democratização das próprias estruturas do Estado (Santos, 1999), além de promover e ampliar as capacidades estatais em áreas em que o Estado tem limites de eficiência e efetividade (Abers e Keck, 2008; Pires e Vaz, 2012).

\section{A Consulta Popular: um processo participativo institucionalizado em nível supralocal}

O estado do Rio Grande do Sul (RS) está localizado no extremo sul do Brasil e conta com cerca de 10,7 milhões de habitantes, distribuídos em 497 municípios e em uma superfície territorial total de $281.748 \mathrm{~km}^{2}$. A capital do estado, Porto Alegre, foi onde se originou o Orçamento Participativo (OP), experiência criada em 1989 e que foi posteriormente difundida pelo Brasil e pelo mundo (Sintomer et al., 2010; Wampler e Avritzer, 2006).

Dentro de uma disputa política que surgiu a partir do sucesso do OP de Porto Alegre, em 1998, um governo de centro-direita criou e institucionalizou por meio de lei estadual a CP, processo no qual a população do estado decide - direta e anualmente - a destinação de parcela do orçamento gaúcho voltada a investimentos de interesse regional. Diversas atribuições de coordenação e implementação da CP são executadas pelos Conselhos Regionais de Desenvolvimento (Coredes), entidades colegiadas compostas por representantes da sociedade civil e política gaúchas. 
Figura 1

Consulta Popular - Ciclo orçamentário anual

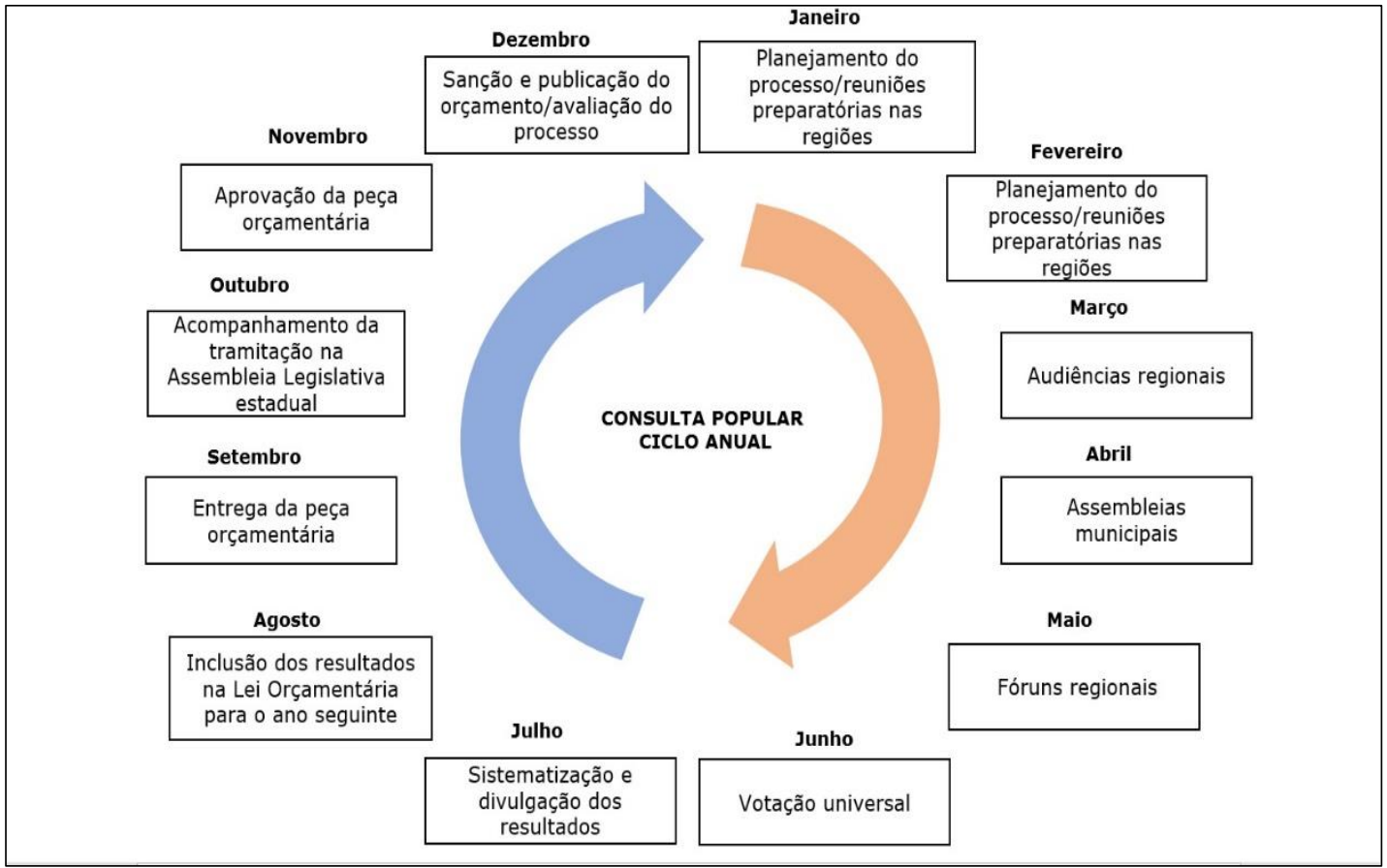

Fonte: Adaptado pelo autor a partir de modelo adotado pela Secretaria de Planejamento - Seplan (RS).

De um modo geral, e apesar de contar com variações ao longo de seus mais de 20 anos de existência, o ciclo anual da CP (ver Figura 1) se inicia com o governo estadual definindo o orçamento anual destinado a ela. Na sequência, as linhas gerais do processo são discutidas com os Coredes em audiências públicas regionais. E depois realizam-se assembleias públicas municipais organizadas pelos Conselhos Municipais de Desenvolvimento (Comudes). As assembleias municipais são abertas à participação direta e universal de todos os cidadãos residentes nos municípios, em que são sugeridas prioridades e escolhidos representantes. Na próxima etapa, os Coredes coordenam fóruns regionais em cada uma das 28 regiões de planejamento do estado. Os fóruns são abertos a todos os cidadãos, com direito a voz. Já o voto é restrito aos membros dos Coredes e aos delegados eleitos nas etapas municipais. Após processo de mobilização realizado pelos Coredes e Comudes, tais conselhos organizam a votação universal, atualmente feita integralmente online. Cada eleitor vota para escolher as demandas prioritárias em cada região. Por fim, os Coredes sistematizam os resultados da votação e os encaminham para o governo, onde integram a lei orçamentária para o ano subsequente. Por fim, os Coredes acompanham a execução das demandas eleitas. As relações entre os diversos atores estão representadas graficamente na Figura 2: 
Figura 2

Modelo de gestão da CP - Principais etapas e atores

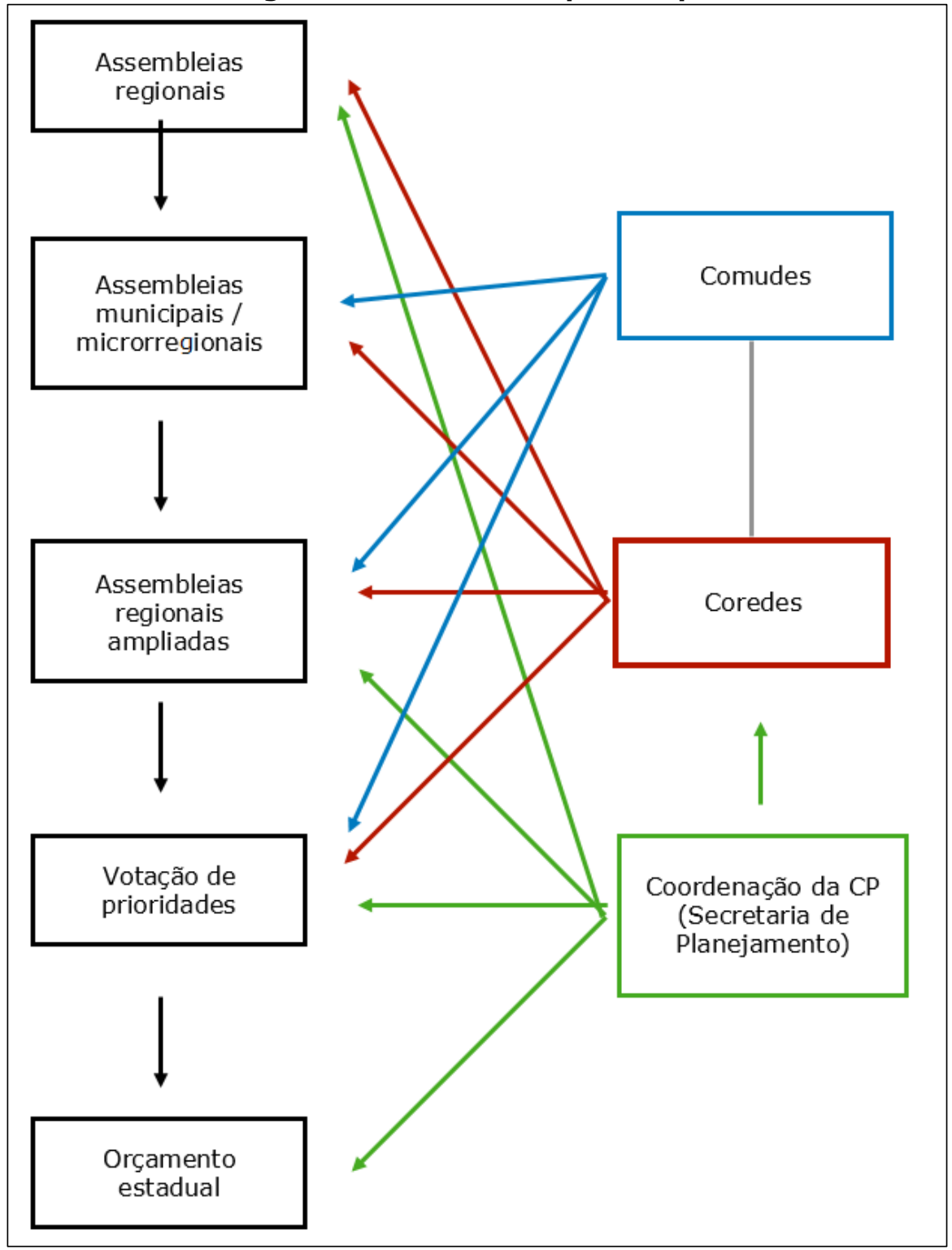

Fonte: Elaboração própria a partir dos dados empíricos coletados pelo autor. 


\section{Consulta Popular: uma trajetória de 20 anos}

Esta seção apresenta a síntese da reconstrução histórica da CP realizada a partir da metodologia do process tracing. Por questões de limites de espaço, se enfatizará aqui apenas os momentos-chave que contribuem para explicar o perfil e as mudanças estruturais na condução e na orientação da CP em cada "fase" de sua implementação.

As origens da CP remontam à tradição gaúcha na promoção de mecanismos de participação social (Allebrandt, 2010; Bandeira, 2007). Apesar de contar com um histórico marcado pelo autoritarismo, o Rio Grande do Sul vivenciou uma intensificação do associativismo, do cooperativismo e do ativismo social durante o século $X X$, que gerou novas dinâmicas a partir do processo de redemocratização brasileira (Brose, 2010). Tais dinâmicas levaram à criação e consolidação do OP. Nesse contexto, destaca-se o papel das universidades regionais que, para além de dotar os pequenos municípios do interior de uma elite cultural relevante, mantiveram fortes vínculos com a sociedade civil e política locais e regionais.

Com fortes vínculos com as universidades regionais, foram criados os Conselhos Regionais de Desenvolvimento, que impulsionaram a conformação do desenvolvimento regional como tema de políticas públicas em um estado marcado por profundas desigualdades regionais. Tal tema entrou formalmente no âmbito do Estado durante o governo trabalhista de Alceu Collares, do Partido Democrático Trabalhista (PDT). Entre 1991 e 1994, os Coredes foram criados, consolidados e, posteriormente, institucionalizados pela Lei 10.238/1994. A criação dos Coredes é o primeiro momentochave que permite compreender a evolução da CP. Explica por que, até o presente momento, a CP tem vínculos fortes com as universidades regionais e com os municípios do interior do estado (mais do que com Porto Alegre e sua região metropolitana). Contribui também para explicar por que a influência da CP foi direcionada para as políticas de desenvolvimento regional.

Às vésperas de eleições estaduais, em 1998, o governo de centro-direita chefiado por Antônio Britto, do então Partido do Movimento Democrático Brasileiro (PMDB) (19951998), aprovou a Lei 11.179/1998, que visava realizar uma consulta direta à população sobre quais ações ou políticas de interesse regional deveriam ser incluídas no orçamento estadual. Tal iniciativa pode ser analisada como uma resposta ao OP, que estava em seu auge em municípios como Porto Alegre e que contribuía para o favoritismo eleitoral do Partido dos Trabalhadores (PT) ao governo estadual. A institucionalização da CP é vista como um momento-chave em sua trajetória.

Apesar de a CP ter sido proposta pelo núcleo do governo Britto, sem a participação direta dos Coredes em sua concepção, tais conselhos aceitaram assumir as atribuições de coordenação da Consulta, conforme estipulado na lei de criação da CP. A primeira edição da CP mobilizou expressivos 379.205 eleitores, que escolheram prioridades de políticas públicas a partir das alternativas disponíveis em uma lista elaborada pelos Coredes. 
Diferentemente do OP de Porto Alegre (criado por um governo de esquerda chefiado pelo PT) - que era focado nas assembleias locais, na participação face a face e na inclusão de grupos social e politicamente marginalizados -, o modelo da CP criado pelo PMDB enfatizou a votação universal em uma tentativa de incluir um maior número de participantes, em uma escala supralocal, e de buscar maior eficiência no uso de recursos públicos. Um exemplo disso é que o governo estadual optou por não contar o número de participantes nas etapas em que se daria a participação face a face. A Tabela 1 apresenta os dados consolidados da CP entre 1998 e 2018:

Tabela 1

Consulta Popular - Dados consolidados (1998-2018)

\begin{tabular}{|l|c|c|c|c|c|c|}
\hline Ano & $\begin{array}{c}\text { Votos em } \\
\text { urna }\end{array}$ & $\begin{array}{c}\text { Votos via } \\
\text { internet, } \\
\text { SMS e } \\
\text { aplicativo }\end{array}$ & $\begin{array}{c}\text { Total de } \\
\text { votos }\end{array}$ & $\begin{array}{c}\text { Percentual de } \\
\text { eleitores (\%) }\end{array}$ & $\begin{array}{c}\text { Recursos } \\
\text { destinados à CP } \\
\text { (em reais) }\end{array}$ & $\begin{array}{c}\text { Participantes } \\
\text { em etapas } \\
\text { intermediárias } \\
\text { (assembleias } \\
\text { regionais + } \\
\text { municipais) }\end{array}$ \\
\hline 1998 & 379.205 & - & 379.205 & 5,7 & 100 milhões & s/d \\
\hline $\begin{array}{l}1999 \\
\text { (OPE*) }\end{array}$ & 188.528 & - & 188.528 & 2,7 & Não definido & 188.528 \\
\hline $\begin{array}{l}2000 \\
\text { (OPE) }\end{array}$ & 281.926 & - & 281.926 & 3,9 & Não definido & 281.926 \\
\hline $\begin{array}{l}2001 \\
\text { (OPE) }\end{array}$ & 378.340 & - & 378.340 & 5,3 & Não definido & 378.340 \\
\hline $\begin{array}{l}2002 \\
(\mathrm{OPE})\end{array}$ & 333.040 & - & 333.040 & 4,5 & Não definido & 333.040 \\
\hline 2003 & 459.155 & 3.137 & 462.292 & 6,3 & 310 milhões & $\mathrm{s} / \mathrm{d}$ \\
\hline 2004 & 574.891 & 6.224 & 581.115 & 7,7 & 337 milhões & $\mathrm{s} / \mathrm{d}$ \\
\hline 2005 & 629.526 & 44.549 & 674.075 & 8,9 & 202 milhões & $\mathrm{s} / \mathrm{d}$ \\
\hline 2006 & 640.998 & 85.982 & 726.980 & 9,4 & 310 milhões & $\mathrm{s} / \mathrm{d}$ \\
\hline 2007 & 329.680 & 39.737 & 369.417 & 5,6 & 40 milhões & $\mathrm{s} / \mathrm{d}$ \\
\hline 2008 & 428.809 & 49.501 & 478.310 & 7,1 & 50 milhões & $\mathrm{s} / \mathrm{d}$ \\
\hline 2009 & 813.700 & 136.377 & 950.077 & 11,9 & 115 milhões & $\mathrm{s} / \mathrm{d}$ \\
\hline 2010 & 1.039 .471 & 177.596 & 1.271 .067 & 15,0 & 165 milhões & $\mathrm{s} / \mathrm{d}$ \\
\hline 2011 & 998.145 & 135.996 & 1.134 .141 & 13,9 & 165 milhões & 66.400 \\
\hline 2012 & 907.146 & 121.551 & 1.028 .697 & 12,3 & 165 milhões & 65.700 \\
\hline 2013 & 967.610 & 157.549 & 1.125 .159 & 13,5 & 165 milhões & 75.904 \\
\hline 2014 & 1.059 .642 & 255.751 & 1.315 .393 & 15,6 & 165 milhões & 85.221 \\
\hline 2015 & 443.761 & 121.797 & 565.558 & 6,7 & 60 milhões & $\mathrm{s} / \mathrm{d}$ \\
\hline 2016 & - & 405.541 & 405.541 & 4,8 & 50 milhões & 22.847 \\
\hline 2017 & - & 705.835 & 705.835 & 8,5 & 60 milhões & $\mathrm{s} / \mathrm{d}$ \\
\hline 2018 & - & 794.312 & 794.312 & 9,5 & 80 milhões & $\mathrm{s} / \mathrm{d}$ \\
\hline
\end{tabular}

Fonte: Elaboração própria a partir de dados de Allebrandt (2010), Silva e Gugliano (2014), GRS (2002, 2014a) e documentos internos do governo do RS. *OPE - Orçamento Participativo Estadual.

Apesar da criação da CP, o PMDB perdeu as eleições e a esquerda chegou ao poder com Olívio Dutra, do PT (1999-2002), que concretizou uma promessa feita durante a campanha eleitoral de levar O OP à escala estadual. O governo Dutra implantou o 
Orçamento Participativo Estadual (OPE) mantendo um desenho institucional muito próximo ao OP de Porto Alegre (com ênfase na inclusão política e participação presencial) e nomeando coordenadores regionais para atuar como mobilizadores nas diversas regiões do estado. O problema é que, em tais regiões, houve conflitos entre os coordenadores regionais nomeados pelo PT e os Coredes, que passariam a não ter mais privilégios na discussão do orçamento estadual. A primeira mudança de governo enfrentada pela CP constitui outro momento-chave. Foi nesse contexto que foi ativado um mecanismo que será recorrente em todas as transições de governo subsequentes e que é fator central para explicar sua resiliência: o ativismo político dos Coredes e o uso político (e jurídico) da lei que institucionalizou a CP.

Os Coredes advogaram a legitimação da CP realizada no ano anterior, por meio da implementação das propostas eleitas e da retomada da centralidade desses conselhos na discussão orçamentária, conforme explicitado nas leis dos Coredes e da Consulta Popular. Tal impasse gerou um conflito de grande escala, com ampla divulgação na mídia e contemplando ramificações judiciais. Em um primeiro momento, os Coredes aliaram-se ao Poder Legislativo estadual - majoritariamente de oposição ao PT - e novas formas de participação "concorrentes"7 ao OPE foram criadas pelo Coredes e pela Assembleia Legislativa, enquanto se tentava judicialmente a suspensão do OPE.

Após cerca de seis meses de intenso conflito, os Coredes e o governo estadual fizeram um acordo, alterando o desenho institucional do OPE para dar maior espaço aos Coredes em seu interior. Assim, elementos típicos da CP foram restaurados, a começar pela maior influência dos Coredes na coordenação do processo. O Orçamento Participativo Estadual continuou ativo nos quatro anos seguintes, com ampliação de participantes ao longo do tempo e uma redução dos conflitos, sendo tal redução maior ou menor conforme a região de planejamento do RS. O acordo realizado entre os Coredes e o governo petista é momento importante na trajetória da CP. A partir de então, a experiência passou a contar com maior intensidade participativa em suas fases intermediárias, o que se refletiu em um desenho institucional que previa a eleição de delegados entre as etapas municipais e regionais e uma maior ênfase na mobilização e na inclusão de grupos marginalizados. Tais inovações são exemplos das características estimuladas pelos governos de esquerda, que tendem a enfatizar a mobilização contínua, os diálogos face a face, a construção conjunta de propostas e a inclusão política. Os números quantificados referiram-se aos cidadãos que participaram em todas as etapas do processo (ver Tabela 1).

No entanto, por não estar formalmente institucionalizado, o OPE teve fim após nova mudança de governo, quando o governador Germano Rigotto (PMDB) restaurou o processo institucionalizado da CP. A restauração da CP nos moldes do governo Britto foi também proposta de campanha do candidato do PMDB. Nesse contexto, e antes de assumir o principal cargo do Executivo, o governador eleito Rigotto afirmou, em entrevista ao jornal Zero Hora, de 28 de dezembro de 2002, que

\footnotetext{
7 Notadamente o Fórum Democrático de Desenvolvimento Regional (FDDR).
} 
Não há como governar sem participação popular. Agora, o Orçamento Participativo não é a única forma de participação popular. O OP teve méritos, mas nem sempre aquilo que é decidido em assembleia se transforma em obra. Há denúncias de manipulação em assembleias. Não podemos desconhecer que o Rio Grande do Sul foi um dos pioneiros na busca da participação popular e temos que dar crédito a quem produziu isso. A participação popular deve começar pelos Coredes, os Conselhos Regionais de Desenvolvimento. Eles têm de estabelecer estratégias de desenvolvimento e prioridades de cada região e depois devemos submeter essas demandas a uma Consulta Popular. Não existe uma lei que regulamente o OPE. A Consulta Popular está prevista em lei (apud Allebrandt, 2010, p. 179).

Durante o governo de centro-direita de Rigotto, a CP inicia um período de consolidação institucional. A CP fortaleceu a autonomia dada aos Coredes e a ênfase em uma política formalmente institucionalizada. Aos Coredes cabia coordenar o processo, e o momento-chave da participação social seria a votação universal e não o processo de elaboração de propostas. Apesar disso, a nova CP terminou por incorporar diversos elementos do OPE, em um modelo que Allebrandt (2010), Bandeira (2007) e Silva e Gugliano (2014) avaliaram como híbrido entre a Consulta Popular original (de 1998) e o Orçamento Participativo Estadual, que esteve em vigor durante o governo Dutra.

Apesar de ser mais indireto e menos intensivo que o OPE no sentido de mobilização e participação, a CP gerou uma solução interessante para tratar o problema do scaling-up: a votação universal de prioridades, que permitiu ampliar significativamente a participação. A quantidade de eleitores que votaram na etapa final do processo cresceu consistentemente nos quatro anos do governo do PMDB, atingindo 726.980 eleitores em 2006, último ano do governo.

Apesar do sucesso em torno da institucionalização e da consolidação do modelo da $\mathrm{CP}$, o governo Rigotto não conseguiu implementar adequadamente as demandas votadas, aumentando aquilo que entrevistados denominaram de "passivo", o que gerou críticas oriundas dos Coredes e um certo descrédito na efetividade do instrumento (Allebrandt, 2010; Silva e Gugliano, 2014). Embora os recursos destinados à CP tenham sido superiores a 300 milhões de reais em três dos quatro anos de mandato, a execução das demandas foi muito baixa, chegando a 34\% (ou 118 milhões de reais) em 2005 (Allebrandt, 2010, p. 188).

No início do governo Ieda Crusius (PSDB), em 2007, houve uma tentativa de suspender a $\mathrm{CP}$, tendo em vista o aumento do passivo. Em mais um momento crítico de sua trajetória, o fato de a CP ser institucionalizada foi determinante para a sua manutenção. A força da lei e o ativismo dos Coredes garantiram sua continuidade, ainda que tenha sido necessário renegociar o volume de recursos destinados ela, que foi reduzido entre 2007 e 2008. Contudo, após essa redução dos recursos e a diminuição do número de eleitores na votação universal, a CP retomou sua vitalidade nos últimos dois anos do governo do PSDB. Isso ocorreu porque esse governo e os Coredes pactuaram um termo 
de ajuste em que o governo Crusius se comprometeu a reduzir o "passivo" da CP, enfatizando a eficiência no uso dos recursos e a implementação das demandas eleitas. Após redução inicial nos recursos disponibilizados e no número de votantes, o quadro foi invertido nos dois anos finais e 2010 registrou 1.271 .067 de eleitores, em um processo que disponibilizou 165 milhões de reais para projetos de desenvolvimento regional.

Ao final do mandato do PSDB, o modelo da Consulta Popular estava consolidado na política estadual, sendo importante para o surgimento e o enraizamento de uma identidade regional, sobretudo em Coredes do interior e em municípios menos populosos, que contavam firmemente com os repasses da CP para a implementação de ações (Bandeira, 2007).

Durante os anos de 2011 a 2014, a esquerda volta ao poder com o governador Tarso Genro (PT). Durante esse período, a Consulta Popular foi integrada ao ambicioso projeto do Sistema Estadual de Participação Popular e Cidadã (Sisparci), que buscou tratar a participação de forma complexa e sistêmica. A partir de um diagnóstico que apontava a sobreposição e a baixa articulação entre as várias IPs em vigor no estado, bem como acentuava os limites das formas tradicionais e presenciais de participação, o governo petista buscou promover a articulação entre os diversos mecanismos e ampliar as formas digitais (online) de participação e deliberação.

Para além de valorizar as formas existentes (tais como conselhos e conferências estaduais), o governo petista criou novas instituições para a promoção do diálogo entre Estado e sociedade civil, vinculadas diretamente ao gabinete do governador. Entre as novas instituições, destacam-se o Gabinete Digital (GD), responsável pelas novas formas não presenciais de participação, e o Conselho Estadual de Desenvolvimento Econômico e Social (CDES). Na tentativa de evitar novo conflito com os Coredes e com o Legislativo estadual (como ocorrido durante o governo de Olívio Dutra, entre 1999 e 2002), o governo petista reconheceu a existência da $\mathrm{CP}$, atuando no sentido de ampliar sua intensidade democrática e de articulá-la com as demais instâncias participativas.

Embora ambiciosa, a perspectiva sistêmica do governo Tarso Genro pouco avançou para além do âmbito teórico. Apesar de ter contado com novas instituições participativas relativamente bem-sucedidas (notadamente o GD e o CDES), a articulação entre as diversas instituições participativas não ocorreu como era esperado. Ao longo da experiência do Sisparci, contudo, a CP foi paulatinamente ganhando espaço e tornou-se, ao fim do governo, a principal "vitrine" do sistema. Isso ocorreu porque o PT resolveu adotar e potencializar a experiência maturada nos governos anteriores, mantendo a centralidade dos Coredes e evitando conflitos com uma forma já enraizada de participação social, fundamental sobretudo em municípios do interior do estado.

Em mais um momento-chave na trajetória da $\mathrm{CP}$, os Coredes utilizaram-se de seu "ativismo" para garantir a manutenção, em linhas gerais, de seu desenho institucional. No entanto, o governo de esquerda também conseguiu influenciar o perfil do processo durante os anos de 2011 a 2014. A partir de negociações com os Coredes, mudanças pontuais no 
desenho institucional permitiram maior mobilização e participação nas etapas preliminares, realizadas em todos os municípios e regiões do estado, aumentando assim a intensidade democrática do processo.

De forma diversa ao ocorrido nos governos anteriores de centro-direita, o número de participantes nas etapas de construção de propostas foi novamente calculado, atingindo 85.221 participantes nas etapas preliminares. A quantidade de eleitores que participaram da votação universal manteve-se alta, com média superior a 1 milhão de eleitores por ano e atingindo, em 2014, a cifra recorde de 1.315 .393 votantes. Por meio da articulação com o GD, a CP, além de adotar a votação presencial, passou a permitir o voto online.

A CP, promovida no âmbito do Sisparci, foi premiada pelas Nações Unidas em 2013 e foi considerada pelo governo (GRS, 2014b), pelo Banco Mundial (Peixoto, Sjoberg e Mellon, 2017) e por diversos autores (Goldfrank, 2014; Spada et al., 2015; Mellon, Peixoto e Sjoberg, 2017) como sendo a maior experiência de orçamento participativo já existente, ainda que se tratasse de uma forma mais ampla e menos intensa de OP.

A evolução do Sisparci foi interrompida após nova eleição, na qual o PMDB voltou ao governo com a eleição de José Ivo Sartori (2015-2018). Em um governo marcado por crise econômica, corte de gastos e redução do tamanho do Estado, as instituições participativas criadas durante o governo anterior foram descontinuadas e a perspectiva sistêmica, não institucionalizada, não foi mantida.

A Consulta Popular, por sua vez, continuou ativa, apesar de ter enfrentado tentativas de suspensão durante o ano de 2015. Alegando dificuldades financeiras, o governo Sartori relutava em dar continuidade ao processo. Em mais um momento importante na trajetória da $\mathrm{CP}$, a lei que a institucionalizou teve papel importante na sua manutenção. Não realizar a CP poderia gerar problemas jurídicos para o novo governador, em início de mandato. A mobilização e a pressão exercidas pelos Coredes também contribuíram para a sua continuidade, mesmo em um governo em que a participação social não ocupou lugar central e prioritário nas políticas públicas.

No entanto, novo equilíbrio teve que ser buscado e a CP teve seu escopo reduzido a partir de 2015. Os recursos destinados ao processo sofreram uma redução, de 165 milhões de reais anuais entre 2011 e 2014 para 50 milhões em 2016. A mobilização durante as etapas intermediárias também foi reduzida, passando de 85.221 participantes em 2014 para 22.847 em 2016. Por fim, o número de eleitores, que atingiu 1.315 .393 em 2014, sofreu redução para 405.541 em 2016.

Em linha com os governos de centro-direita anteriores, a CP no governo Sartori enfatizou menos a mobilização e a inclusão política e mais questões relacionadas à eficiência na execução das propostas eleitas, mesmo que isso implicasse uma menor intensidade participativa e um recuo na mobilização e participação. O argumento da austeridade econômica também foi central para a decisão de eliminar a possibilidade de voto presencial em urna. Utilizando as bases iniciadas durante o governo Tarso Genro, a votação universal passou a ser realizada exclusivamente online (via internet, por SMS e por aplicativos de celular) a partir de 2016. 
Enquanto o governo Tarso priorizava a mobilização em torno das etapas preliminares e a quantidade de votantes, as etapas preliminares no governo do PMDB foram muito menos intensas do ponto de vista da participação, com queda significativa no número de participantes e casos em que municípios optaram por realizar conjuntamente assembleias microrregionais para grupos de municípios, em vez de uma assembleia em cada município, como foi o padrão no governo de esquerda anterior.

Por outro lado, enfatizou-se a execução das demandas eleitas. Durante o governo do PT, o passivo da CP cresceu. O novo governo atuou no sentido de minorar o passivo deixado pela gestão anterior e de não criar novos passivos. A partir da normatização de fluxos de implementação, do aumento da integração das demais secretarias ao processo da Consulta e do acompanhamento ostensivo da execução das demandas, o governo do PMDB conseguiu aumentar o percentual de execução das demandas eleitas, que atingiu $83 \%$ em 2016.

O aumento na execução das demandas eleitas deu um novo fôlego para a CP. Em 2017, os recursos voltaram ao patamar de 60 milhões, atingindo 80 milhões em 2018. Já a quantidade de eleitores subiu paulatinamente nos últimos dois anos do governo Sartori: 2017 contou com 705.835 votos e a edição de 2018 registrou novo aumento, alcançando a marca de 794.312 eleitores.

\section{Discussão: inovações institucionais e resiliência da Consulta Popular}

Tendo em vista a riqueza e a longa trajetória histórica da experiência, a Consulta Popular é útil para discutir diversas questões que estão presentes tanto nas teorias democráticas quanto na análise de instituições participativas. Não é objetivo deste artigo explorar de forma exaustiva todas essas questões. Não obstante, é útil abordar, de forma mais estruturada, três dimensões de análise enfatizadas no referencial teórico e na pesquisa empírica. A primeira subseção a seguir retoma a discussão sobre escala e participação a partir da experiência da CP. A segunda discute, por sua vez, os fatores que explicam a resiliência da $\mathrm{CP}$ às mudanças de governo. $\mathrm{E}$ a terceira mostra como a $\mathrm{CP}$, criada por um governo de centro-direita, teve suas características e objetivos mantidos ou alterados conforme o perfil ideológico de cada governo estadual.

\section{Combinando participação e processos eleitorais em nível supralocal}

Do ponto de vista teórico, a CP apresenta resultados ambíguos: ao mesmo tempo que tende a confirmar pressupostos clássicos da teoria da democracia que apontam o aumento de escala como redutor da intensidade democrática (Dahl e Tufte, 1973), essa experiência mostra que, ao contrário da visão defendida por autores da democracia representativa (tais como Bobbio, 1997; Schumpeter, 1961), o voto universal pode ser utilizado com proveito não só para eleger representantes e para realizar plebiscitos e 
referendos, mas também como instrumento efetivo para mobilizar parcelas significativas da população em processos regulares de definição direta de políticas públicas.

A questão da escala também é enfrentada a partir da representação no interior das experiências de participação (Lüchmann, 2007). Tais tipos de representação assumem duas formas distintas na CP. A primeira reproduz o formato clássico das experiências de Orçamento Participativo: um número de delegados proporcional ao número de indivíduos presentes nas assembleias municipais é eleito para atuar como representante nas instâncias superiores. No entanto, diferentemente do OP, tais delegados passam a atuar conjuntamente com os membros dos Coredes. A legitimidade representativa de tais colegiados é oriunda não de eleições, mas da sustentação política e social que recebem da sua formalização por meio de lei, aliada ao seu trabalho em municípios do interior, em torno da agenda do desenvolvimento regional. Tal agenda passa a articular uma identidade comum aos "coredianos", a partir de formas de representação por afinidade (Avritzer, 2007).

A CP constitui uma forma inovadora de salto de escala, pois consegue combinar processos participativos, deliberativos e eleitorais em um desenho institucional composto por etapas intermediárias marcadas pela interação face a face, seguidas por votações universais regulares anuais em que são definidas obras e políticas públicas de interesse regional. Ainda que seja menos intenso do que recomenda o modelo habermasiano ideal de deliberação (Sobottka e Streck, 2014), a Consulta pode ser considerada um exemplo de participação e deliberação "boa o suficiente" (Bächtiger et al., 2010; Goodin, 2005), erigido a partir da tradição política gaúcha, com suas potencialidades e limitações. Dessa forma, o modelo da CP permite atingir uma grande quantidade de participantes e uma significativa mobilização social, sobretudo em municípios do interior sul-rio-grandense, contornando de forma relativamente eficaz os limites postos pela extensão territorial, pelo número de habitantes e pela complexidade administrativa típica de níveis supralocais.

Se, por um lado, o modelo da Consulta Popular permite contornar os limites do scaling-up da participação e da deliberação, por outro lado, não consegue resolvê-los. No modelo analisado, a tensão entre complexidade social e soberania popular (Faria, 2007) continua presente. Apesar da eficiência do processo no que tange aos seus principais resultados, a CP apresenta alguns limites claros. Além da já mencionada baixa intensidade democrática quando comparada aos processos participativos locais, é possível citar: a) o predomínio das demandas locais em relação às regionais no interior do processo participativo supralocal; e b) as dificuldades de incorporação da CP no interior das administrações públicas.

Apesar de ser esperado que a CP, processo supralocal, seja centrada em escolhas políticas mais amplas, estruturantes e complexas, as demandas de caráter local tendem a predominar durante a votação. Isso ocorre porque tais demandas aparentam ter maior potencial de assegurar uma mobilização constante em torno de si. Grupos sociais locais (professores, policiais, bombeiros, associações de bairro, entre outros) veem na CP uma oportunidade de realização de pequenas obras e ações em um contexto em que os recursos 
para os pequenos municípios são escassos. Assim sendo, tais grupos sociais fazem campanha eleitoral e mobilizam os eleitores de determinada região para votarem nas demandas de seu interesse.

O cidadão comum, por sua vez, tende a escolher as propostas locais, cujo resultado é mais palpável e imediato, não direcionando recursos para ações e políticas estruturantes em macroescala. Apesar de a coordenação da CP ter, ao longo do tempo, testado diversas alternativas metodológicas para garantir um direcionamento mínimo de recursos para demandas mais complexas em escala regional (denominado pelos membros dos Coredes entrevistados de "atacado"), os projetos e ações de caráter fundamentalmente local (denominadas "varejo") continuam a predominar em vários municípios e regiões. Isso induz a uma contradição que aponta que, embora a CP seja um processo participativo supralocal, boa parte dos seus recursos e ações são destinados para o nível local, pouco abordando as complexidades inerentes às escolhas e políticas públicas em larga escala.

\section{Resiliência e participação: o círculo virtuoso entre os Coredes e a institucionalização}

É argumento corrente que as instituições participativas são vulneráveis a mudanças de governo e mantêm-se, muitas vezes, ligadas ao partido político ou ao gestor que as criou. Com uma trajetória de mais de 20 anos e tendo sobrevivido a seis mudanças de governo, cada qual com sua própria ideologia, a CP é incomumente resiliente. O tema conseguiu atingir um status suprapartidário (Goldfrank e Schneider, 2006; Faria, 2006; Cortes, 2003). As disputas em torno da questão conseguiram ir além do binômio de ter ou não ter mecanismos de participação direta da população no orçamento, para concentrarse na disputa sobre qual o modelo participativo mais adequado para o RS.

$\mathrm{O}$ process tracing realizado na pesquisa que deu origem a este artigo identificou as transições governamentais como sendo momentos-chave na trajetória da CP. Durante tais transições, foi identificado um padrão que recorrentemente foi mobilizado quando a sua continuidade esteve ameaçada. Esse padrão é denominado aqui de círculo virtuoso estabelecido entre a coalizão de defesa (Sabatier e Weible, 2007) em torno da política e as leis que a institucionalizam.

A coalizão de defesa é liderada pelos Coredes, que são um dos pilares de sustentação da CP. Em diversos momentos, a pressão e a atuação dos Coredes foram fundamentais para manter, organizar e promover as Consultas. No entanto, é fundamental compreender que o surgimento e a consolidação dos Coredes são anteriores às CPs e que as atribuições dos Conselhos e suas articulações com o governo e com a sociedade vão além dos processos de participação no orçamento. Os Coredes foram apropriados por organizações da sociedade civil, por representantes de governos municipais e pelas universidades regionais, tornando-se canal fundamental de promoção dos interesses regionais. 
É importante mencionar que, apesar de contar com representantes vinculados a diferentes linhas político-partidárias, os Coredes não pretendem ser apolíticos. Ao contrário, as disputas partidárias reproduzem-se no interior desses conselhos, que contam com representantes ligados aos diversos partidos presentes no espectro político estadual. No entanto, e apesar da variação entre os 28 Coredes existentes, foi possível o estabelecimento de uma "identidade corediana", que foi capaz de, na maioria dos casos, prevalecer sobre os vínculos partidários (Allebrandt et al., 2011).

Para compreender como foi possível a construção dessa "independência", é útil levar em conta a constituição jurídica dos Coredes (e do Fórum dos Coredes), que são formalmente associações privadas sem fins lucrativos ${ }^{8}$, ou seja, têm uma relação com o governo diferente daquela que tem a maioria dos outros conselhos estaduais de políticas públicas, que são diretamente vinculados ao aparato governamental (Guimarães e Martins, 2013).

Apesar de institucionalizados e recebendo - por lei - recursos governamentais para sua manutenção e para a realização da $\mathrm{CP}$, estes e outros repasses de verbas são feitos aos Coredes por meio de convênios, de maneira semelhante a uma organização não governamental (Allebrandt et al., 2011), por exemplo. O resultado disso é que os Coredes não são completamente dependentes da administração pública estadual. Se tal dimensão aproxima os Coredes de grupos de interesse privados, também garante sua continuidade e vitalidade após múltiplos governos estaduais.

Se, por um lado, a perenidade e a vitalidade da Consulta Popular podem ser creditadas aos Coredes, por outro lado, é fundamental apontar a importância da lei que institucionalizou a CP em 1998 e suas modificações posteriores. Entrevistados de diversos setores apontam que a Consulta só existe porque foi criada por meio de lei e que essa lei garantiu sua continuidade.

O papel-chave da lei pôde ser sentido durante as transições de governo e em momentos em que os governos estaduais não priorizaram a CP. Foi a lei da Consulta Popular que sustentou a atuação dos Coredes quando o governo petista de Olívio Dutra quis substituir a CP pelo modelo do OPE. Foi a existência da lei que garantiu a manutenção da CP no início do governo Ieda Crusius (PSDB), quando o alto passivo deixado pelo governo de esquerda e o foco no corte de gastos serviram como justificativa para uma tentativa de suspender a Consulta Popular. O suporte fornecido pela lei da CP também foi determinante para que essa consulta tenha sido central e bem estruturada quando o governo Tarso (PT) promoveu o Sisparci. Por fim, a lei da CP foi determinante para a manutenção do processo durante o governo Sartori (PMDB), em um mandato marcado por crise econômica e não priorização de mecanismos de participação social.

\footnotetext{
8 No ordenamento jurídico brasileiro, as associações privadas sem fins lucrativos são entidades de direito privado cujo objetivo final não pode ser o lucro. São exemplos de organizações privadas sem fins lucrativos as organizações não governamentais e diversas associações, como as de classe, de moradores, religiosas, entre outras.
} 
Apesar de estar clara a importância da institucionalização para explicar a perenidade, também está claro que se não tivesse sustento político e social, dificilmente a lei da CP conseguiria - por si só - manter ativo o processo. Assim sendo, constitui-se uma relação virtuosa e de mão dupla entre a institucionalização da participação e o ativismo social e político, em que um elemento potencializa o outro. Tal relação torna-se mais forte ao longo do tempo, na medida em que a Consulta Popular passa a fazer parte da tradição política gaúcha.

Uma característica interessante da Lei estadual no 11.179/1998 é que ela foi institucionalizada sem deixar demasiadamente rígido o processo da CP. Ao atribuir a coordenação do processo aos Coredes, a lei garantiu certa flexibilidade ao processo. Assim sendo, o modelo da CP pôde adaptar-se ao perfil de vários governos estaduais.

\section{Eficiência ou inclusão? A Consulta Popular em governos de direita e de esquerda}

As IPs que floresceram no Brasil a partir da década de 1990 são recorrentemente associadas a partidos de esquerda. De fato, o OP de Porto Alegre foi criado e consolidado em governos do PT. A ascensão do mesmo partido ao governo federal em 2003 potencializou o uso dos mecanismos (já existentes) dos conselhos e conferências nacionais.

A perda de espaço do PT e de demais partidos de esquerda no Brasil após o ciclo de manifestações iniciado em junho de 2013 trouxe consigo uma redução na intensidade democrática e o fim de várias IPs. No entanto, deixando à parte os conflitos partidários, há ampla margem para expressão de experiências participativas em governos de direita.

Do ponto de vista formal, os conceitos de participação e, em menor grau, de deliberação foram adotados por atores e grupos tanto da "nova esquerda" quanto da "nova direita" como um elemento importante para a promoção de políticas públicas, ainda que por razões diversas (Mohan e Stokke, 2000; Dagnino, 2002; Sanyal, 2005).

Na visão da "esquerda", a participação e a deliberação tendem a ater-se mais diretamente aos ideais de revitalização e aumento da legitimidade democrática, assim como de inclusão política, redução de desigualdades e cidadania ativa. A participação estaria relacionada com a celebração da diversidade e da integração entre os cidadãos, ressaltando experiências de vida compartilhadas.

Por sua vez, o olhar da "direita" tende a enfatizar o potencial efeito da participação no aumento da eficiência das políticas e na redução de conflitos em torno de intervenções privadas e públicas. O efeito democratizante recai na crença de que a sociedade civil pode exercer pressão em Estados autocráticos e ineficientes, promovendo boa governança e estabilidade política e econômica.

De maneira geral, tanto a perspectiva da "direita" como a da "esquerda" tiveram lugar na CP, ao longo dos seus 20 anos de trajetória. O mais interessante é que, no caso empírico, vários elementos teóricos sobre orientação política e participação foram 
confirmados. A título de ilustração, a Tabela 2 apresenta, para cada governo estadual, as principais ênfases e resultados da CP:

Tabela 2

CP: principais ênfases e resultados (1998-2018)

\begin{tabular}{|c|c|c|c|c|}
\hline Governo & Partido & $\begin{array}{c}\text { Orientação } \\
\text { política }\end{array}$ & Ênfases & Principais resultados \\
\hline $\begin{array}{l}\text { Antônio Britto } \\
\text { (1995-1998) }\end{array}$ & PMDB & $\begin{array}{l}\text { Centro- } \\
\text { direita }\end{array}$ & $\begin{array}{l}\text { - Institucionalização por meio de leis } \\
\text { - Coordenação descentralizada para os } \\
\text { Coredes } \\
\text { - Votação universal }\end{array}$ & $\begin{array}{l}\text { - Criação da CP em } 1998 \\
\text { - Envolvimento formal dos Coredes no } \\
\text { processo }\end{array}$ \\
\hline $\begin{array}{l}\text { Olívio Dura } \\
(1999-2002)\end{array}$ & PT & $\begin{array}{l}\text { Centro- } \\
\text { esquerda }\end{array}$ & $\begin{array}{l}\text { - Institucionalização vista como rigidez e } \\
\text { falta de autonomia } \\
\text { - Criação de instância alternativa de } \\
\text { participação (Orçamento Participativo } \\
\text { Estadual), estimulando a inclusão política de } \\
\text { grupos e movimentos sociais marginalizados } \\
\text { - Conflito com os Coredes (vistos como } \\
\text { "elitistas") } \\
\text { - Foco nas etapas de mobilização e de } \\
\text { participação face a face (construção coletiva } \\
\text { de propostas) }\end{array}$ & $\begin{array}{l}\text { - Implementação do OPE } \\
\text { - Conflito com os Coredes e com o } \\
\text { Legislativo estadual } \\
\text { - Oposição dos adversários políticos } \\
\text { - Movimentos sociais e sindicatos } \\
\text { alinhados ao PT ganham importância. }\end{array}$ \\
\hline $\begin{array}{l}\text { Germano Rigotto } \\
(2003-2006)\end{array}$ & PMDB & $\begin{array}{l}\text { Centro- } \\
\text { direita }\end{array}$ & $\begin{array}{l}\text { - Institucionalização por meio de leis } \\
\text { - Coordenação descentralizada para os } \\
\text { Coredes } \\
\text { - Votação universal }\end{array}$ & $\begin{array}{l}\text { - CP restaurada (fim do OPE) } \\
\text { - Alteração no desenho institucional, } \\
\text { incorporando elementos do OPE } \\
\text { - Número de participantes e recursos } \\
\text { destinados à CP cresce continuamente. } \\
\text { - A disputa passa a ser sobre qual } \\
\text { modelo de participação deve ser } \\
\text { adotado (e não se há ou não } \\
\text { participação). } \\
\text { - Início do período de "consolidação" } \\
\text { da CP } \\
\end{array}$ \\
\hline $\begin{array}{l}\text { Yeda Crusius } \\
(2007-2010)\end{array}$ & PSDB & $\begin{array}{l}\text { Centro- } \\
\text { direita }\end{array}$ & $\begin{array}{l}\text { - Tentativa inicial de suspender a CP (devido } \\
\text { ao aumento do passivo) } \\
\text { - Coredes e institucionalização garantem } \\
\text { manutenção do processo } \\
\text { - Descentralização e coordenação dos } \\
\text { Coredes fortalecida } \\
\text { - Votação universal } \\
\text { - Busca por eficiência administrativa } \\
\text { - Foco na implementação de demandas }\end{array}$ & $\begin{array}{l}\text { - Número de recursos e votantes } \\
\text { reduzido nos primeiros dois anos do } \\
\text { governo } \\
\text { - Redução do passivo } \\
\text { - Número de eleitores volta a } \\
\text { aumentar nos dois últimos anos do } \\
\text { governo. } \\
\text { - Ultrapassa a marca de } 1 \text { milhão de } \\
\text { eleitores em } 2010\end{array}$ \\
\hline
\end{tabular}




\begin{tabular}{|c|c|c|c|c|}
\hline $\begin{array}{l}\text { Tarso Genro } \\
(2011-2014)\end{array}$ & PT & $\begin{array}{l}\text { Centro- } \\
\text { esquerda }\end{array}$ & $\begin{array}{l}\text { - Experiência do Sistema Estadual de } \\
\text { Participação (Sisparci) } \\
\text { - CP mantida e formalmente integrada ao } \\
\text { Sisparci } \\
\text { - Relação positiva do governo com os } \\
\text { Coredes } \\
\text { - Ênfase tanto nas etapas de participação } \\
\text { face a face (construção coletiva de } \\
\text { propostas) quanto na votação universal } \\
\text { - Estímulo à inclusão política de grupos e } \\
\text { movimentos marginalizados }\end{array}$ & $\begin{array}{l}\text { - A CP torna-se a vitrine do Sisparci } \\
\text { - Reconhecimento internacional (maior } \\
\text { OP em nível mundial) } \\
\text { - Votantes superam } 1 \text { milhão em todos } \\
\text { os anos } \\
\text { - Recorde de } 1.315 .393 \text { eleitores } \\
\text { - Votação online passa a ser } \\
\text { permitida. } \\
\text { - Aumento do passivo }\end{array}$ \\
\hline $\begin{array}{l}\text { José Ivo Sartori } \\
(2015-2018)\end{array}$ & PMDB & $\begin{array}{l}\text { Centro- } \\
\text { direita }\end{array}$ & $\begin{array}{l}\text { - Tentativa inicial de suspender a CP (devido } \\
\text { ao aumento do passivo) } \\
\text { - Coredes e institucionalização garantem } \\
\text { manutenção do processo. } \\
\text { - Ênfase na eficiência administrativa } \\
\text { - Foco na implementação de demandas }\end{array}$ & $\begin{array}{l}\text { - Número de recursos e votantes } \\
\text { reduzido nos primeiros dois anos do } \\
\text { governo. } \\
\text { - Redução do passivo } \\
\text { - Votação passa a ser exclusivamente } \\
\text { online } \\
\text { - Número de eleitores volta a } \\
\text { aumentar nos dois últimos anos do } \\
\text { governo }\end{array}$ \\
\hline
\end{tabular}

Fonte: Elaboração do autor com base em argumentos discutidos ao longo do artigo.

A partir dos dados e informações coletadas, é possível perceber a repetição de padrões e ênfases entre os governos de centro-direita (Britto, Rigotto, Crusius, Sartori), por um lado, e os governos de centro-esquerda, por outro.

Em linha com os argumentos teóricos apresentados no início desta seção, os governos de direita recorrentemente enfatizaram: a) a participação institucionalizada; b) a votação universal, considerada uma forma mais democrática de participação que a inclusão de grupos sociais "alinhados à esquerda"; e c) a ênfase na participação como forma de aumentar a eficiência no uso dos recursos públicos e na implementação de políticas públicas, como notado na questão da redução do passivo da CP.

Já nos períodos em que a CP operou em governos de centro-esquerda, foram fortalecidos elementos como: 1) a ampla mobilização social ao longo do processo, sobretudo nas etapas de construção coletiva de propostas (cidadania ativa); 2) a inclusão política de grupos marginalizados, para além dos Coredes (vistos como "elitistas" por parte da esquerda); e 3) a quantidade de participantes e de recursos destinados à CP torna-se, por vezes, prioritária em relação à implementação das demandas eleitas.

Não obstante as diferenças de ênfases em cada fase da $\mathrm{CP}$, destaca-se como resultado fundamental da $\mathrm{CP}$ a sua resiliência às mudanças de governo e sua crescente consolidação no panorama político gaúcho. Tal resiliência e consolidação são tributárias do já mencionado círculo virtuoso estabelecido entre os Coredes e as leis que institucionalizam a CP. 


\section{Eficiência ou inclusão? A Consulta Popular em governos de direita e de esquerda}

Este artigo reconstruiu a trajetória da Consulta Popular desde suas origens, que remontam ao início da década de 1990 . Por meio da metodologia de rastreamento de processos, foram identificados conjunturas e momentos-chave que explicam as peculiaridades de uma política pública singular, que foi capaz de sobreviver a diversas mudanças de governo e a diferentes orientações político-ideológicas. Um caso único, em que a participação e a deliberação conseguiram ultrapassar barreiras políticas e partidárias. Apesar de ter vínculos com os modelos de OP criados pelo campo da esquerda gaúcha, boa parte da concepção, da institucionalização e da implementação da Consulta Popular ocorreu no interior de governos de centro-direita, o que torna o caso gaúcho útil para analisar a perenidade das políticas participativas ao longo do tempo, bem como as potencialidades e limites de tais políticas em governos conservadores.

Neste artigo, a abordagem teórica e o caso empírico permitem discutir três dimensões centrais para o campo de estudos sobre participação e deliberação. A primeira delas trata do scaling-up da participação, já que o desenho institucional da CP envolve dois níveis de governo (estadual e municipal), em diversas fases durante ciclos anuais.

Do ponto de vista do salto de escala, a experiência sul-rio-grandense pode ser considerada uma forma inovadora e relativamente eficaz de promover a participação e a deliberação em escalas supralocais, na medida em que contorna algumas limitações ao salto de escala.

No caso estudado, foi possível identificar um desenho institucional que combina elementos participativos, deliberativos e eleitorais e que permite a influência de um grande número de cidadãos na definição de ações e políticas públicas a serem diretamente incluídas no orçamento estadual. Trata-se da maior experiência de Orçamento Participativo existente, ainda que sua força quantitativa em termos de inclusão política implique uma redução em sua intensidade democrática, afastando-a dos modelos ideais de boa deliberação para concentrar-se na deliberação possível.

Não obstante, tal experiência também apresenta limites. Se, por um lado, é possível defender o desenho institucional da CP como uma forma que conseguiu contornar, de maneira relativamente eficaz, os limites do salto de escala, por outro lado, é importante dizer que tais limites não foram plenamente resolvidos. A existência de um processo participativo supralocal não conseguiu induzir maior articulação institucional entre os níveis estadual e locais. Apesar de os níveis locais responderem pela grande mobilização em torno da $\mathrm{CP}$, tal onda participativa parece não ter tido efeito sobre a democratização dos processos políticos e decisórios internos aos governos municipais, que continuam a ser predominantemente fechados e pouco transparentes.

A segunda dimensão abordada neste artigo tratou da análise da resiliência dos mecanismos de participação social, que tendem a ser dependentes da vontade política do gestor e vulneráveis a mudanças de governo. A CP é incomumente resiliente, tendo 
sobrevivido a seis mudanças governamentais, sempre alternando entre governos de centro-direita e centro-esquerda, ao longo de uma trajetória que supera duas décadas.

$\mathrm{O}$ artigo mostra que a perenidade da CP remete a uma combinação entre o ativismo dos Coredes (que possuem autonomia relativa em relação ao governo estadual), o enraizamento da Consulta Popular no território gaúcho (especialmente em pequenos municípios do interior) e a institucionalização formal da política por meio de leis.

A partir do diálogo com os Coredes, a CP tornou-se um importante instrumento para governos municipais e para a sociedade civil local no RS, sobretudo em pequenos municípios e em regiões menos desenvolvidas. Em tais localidades, a Consulta é vista como um canal importante de diálogo e influência dos municípios no orçamento estadual, que historicamente beneficiou Porto Alegre e sua região metropolitana.

As leis que institucionalizaram a CP tiveram papel preponderante em garantir a sua continuidade em momentos críticos de mudanças de governo, sendo mobilizadas continuamente pelos Coredes e pelos demais defensores do processo. Trata-se de uma relação virtuosa e de mão dupla, estabelecida entre a institucionalização da participação e o ativismo social e político em torno do tema, em que um reforça o outro.

A força política dos Coredes e seu diálogo com o Poder Legislativo levaram ao aperfeiçoamento da Consulta, em que novas leis foram aprovadas, modificando a lei original. Dessa forma, trata-se de um caso em que a institucionalização da participação contribuiu para a perenidade da política pública sem que essa institucionalização gerasse um engessamento das formas de participação e sem que houvesse um perfil marcado pela cooptação e pelo controle do processo por atores governamentais, não confirmando os receios dos críticos à institucionalização.

Por fim, a terceira dimensão abordada neste artigo trata das ênfases dadas por governos de centro-direita e de centro-esquerda ao longo da trajetória da CP. Discutir as potencialidades e limites de IPs brasileiras em governos de direita tende a ser cada vez mais relevante após as eleições de 2018, em um momento em que a participação social perde centralidade na agenda do governo federal e de diversas administrações estaduais.

Nessa dimensão, ressalta-se que, nos mandatos liderados pelo Partido dos Trabalhadores, a tendência foi buscar a inclusão de grupos politicamente marginalizados, aumentar o número de participantes e promover uma maior intensidade democrática a partir de maior mobilização em torno das assembleias regionais e municipais, momentos em que as propostas são coletivamente construídas. No entanto, em ambos os mandatos petistas, houve um aumento do passivo, isto é, das propostas eleitas mas não implementadas, seja por falta de recursos no momento da execução, seja por problemas administrativos.

Os governos de centro-direita (PMDB e PSDB), por sua vez, mostraram-se confortáveis com a baixa intensidade democrática ao longo de todo o processo e, sobretudo, em suas etapas de interação direta e presencial entre os atores. Esses governos não deram tanta ênfase a elementos como a inclusão política ou a mobilização. Seu foco 
maior foi direcionado à execução das propostas eleitas, mesmo que para isso fosse necessário reduzir o volume de recursos destinados à $\mathrm{CP}$ e, por vezes, ter que lidar com redução na quantidade de eleitores durante a votação universal. Tais governos se pautaram por uma visão em que o objetivo principal da CP é aumentar a eficiência administrativa e proporcionar um processo eficiente de transferência de recursos do governo estadual para os governos municipais.

Durante os governos conservadores, não existiu a intenção formal de que toda a gestão pública fosse guiada pelo princípio participativo. Assim sendo, a experiência da Consulta Popular aponta que, caso a instituição participativa mostre resultados em termos de eficiência na gestão pública e não tenha a ambição de alterar o status quo preestabelecido por meio da inclusão de grupos marginalizados, a participação e a deliberação podem ser toleradas - e mesmo incentivadas - em governos conservadores e de direita.

\section{Referências bibliográficas}

ABERS, R. N.; KECK, M. E. "Representando a diversidade: Estado, sociedade e 'relações fecundas' nos conselhos gestores". Caderno CRH, vol. 21, n 52, p. 99-112, 2008.

ABERS, R. N.; Von BüLow, M. "Movimentos sociais na teoria e na prática: como estudar o ativismo através da fronteira entre Estado e sociedade?". Sociologias, vol. 13, n² 28, p. 52-84, 2011.

Abers, R. N.; Serafim, L.; TAtAgiba, L. "Repertórios de interação Estado-sociedade em um Estado heterogêneo: a experiência na era Lula". Dados - Revista de Ciências Sociais, vol. 57, n² 2, p. 325$357,2014$.

Alencar, J.; Coelho, U. "O decreto sobre a participação social no governo federal e a 'polêmica bendita'". Boletim de Análise Político-Institucional, Ipea, Brasília, n 6, 2014.

AllebrandT, S. L. "Cidadania e gestão do processo de desenvolvimento: um estudo sobre a atuação dos Conselhos Regionais e Municipais de Desenvolvimento do Rio Grande do Sul, de 1990 a 2009". Tese de doutorado em desenvolvimento regional. Universidade de Santa Cruz do Sul, Santa Cruz do Sul, 2010.

AllebrandT, S. L., et al. "Social management and deliberative citizenship: an analysis of the Coredes experience in Rio Grande do Sul, 1990-2010". Cadernos Ebape, vol. 9, n 3, p. 914-945, 2011.

ALmEIDA, D. R. "A relação contingente entre representação e legitimidade democrática sob a perspectiva da sociedade civil". Revista Brasileira de Ciências Sociais, vol. 28, n 82, p. 45-66, 2013.

AlmeidA, D. R.; CunHA, E. S. "Brazilian social assistance policy: an empirical test of the concept of deliberative systems". Critical Policy Studies, vol. 10, p. 1-21, 2016.

AVRITZer, L. Democracy and the public space in Latin America. Princeton: Princeton University Press, 2002.

"Sociedade civil, instituições participativas e representação: da autorização à legitimidade da ação", Dados, vol. 50, n 3, p. 443-464, 2007.

BÄCHTIGER, A., et al. "Disentangling diversity in deliberative democracy: competing theories, their blind spots and complementarities". Journal of Political Philosophy, vol. 18, n 1, p. 32-63, 2010.

BANDEIRA, P. S. "Uma experiência de institucionalização de regiões no Brasil: os Coredes do Rio Grande do Sul". Primeiro Colóquio Internacional sobre Desenvolvimento Territorial Sustentável. Florianópolis, Brasil, 22-25 ago. 2007. 
BARBER, B. Strong democracy: participatory politics for a new age. $3^{a}$ ed. Berkeley, Los Angeles: University of California Press, 2003.

BobBio, N. O futuro da democracia: uma defesa das regras do jogo. $6^{a}$ ed. Rio de Janeiro: Paz e Terra, 1997.

BONAFONT, L. Redes de políticas públicas. Madri: Siglo Vientiuno de España Editores, 2004.

BRoSE, M. Da ditadura positivista à democracia participativa: a expansão da participação popular no Rio Grande do Sul. Santa Cruz do Sul: Edunisc, 2010.

Calmoun, C. (ed.). Habermas and the public sphere. $4^{a}$ ed. Cambridge: The MIT Press, 1996.

Chambers, S. "Deliberative democratic theory". Annual Review of Political Science, vol. 6, n 1, p. 307-326, 2003.

"Rhetoric and the public sphere: has deliberative democracy abandoned mass democracy?". Political Theory, vol. 37, n³, p. 323-350, 2009.

CLEAVER, F. "The inequality of social capital and the reproduction of chronic poverty". World Development, vol. 33, n 6, p. 893-906, 2005.

Cohen, J. Deliberation and democratic legitimacy. In: HAMLIN, A.; PeTtIT, P. (eds.). The good polity: narrative analysis of the State. New York: Basil Blackwell, New York, p. 17-34, 1989.

Cohen, J. L.; ARATo, A. Civil society and political theory. Cambridge: MIT Press, 1994.

Collier, D. "Understanding process tracing". Political Science \& Politics, vol. 44, n 4, p. 823-830, 2011.

COOKE, B.; Kothari, U. (eds.). Participation: the new tyranny?. New York: Zed Books, 2001.

CORTES, S. V. "O governo do estado como protagonista da regionalização e da participação: o caso do Rio Grande do Sul de 1991 a 2003". Caderno CRH, vol. 39, p. 83-103, 2003.

Dagnino, E. (ed.). Sociedade civil e espaços públicos no Brasil. São Paulo: Paz e Terra, 2002.

DAGNino, E.; OlverA, A.; PANFICHI, A. La disputa por la construcción democrática en América Latina. Programa Interinstitucional de Investigación-Acción sobre Democracia, Sociedad Civil y Derechos Humanos. México, DF: Fondo de Cultura Económica, 2006.

DAHL, R. On democracy. New Haven; London: Yale University Press, 1998.

DAHL, R.; TUFTE, E. Size and democracy. Stanford: Stanford University Press, 1973.

DRYZEK, J. S. "Symposium commentary: reflections on the theory of deliberative systems". Critical Policy Studies, vol. 10, n² 2, p. 209-215, 2016.

DrYZeK, J. S.; NiemeYer, S. "Reconciling pluralism and consensus as political ideals". American Journal of Political Science, vol. 50, nº 3, p. 634-649, 2006.

ELSTUB, S.; ERCAN, S.; MENDONÇA, R. F. "Editorial introduction: the fourth generation of deliberative democracy". Critical Policy Studies, vol. 10, p. 139-151, 2016.

FARIA, C. F. "Fóruns participativos, controle democrático e a qualidade da democracia no Rio Grande do Sul: a experiência do governo Olívio Dutra (1999-2002)". Opinião Pública, vol. 12, n² 2, p. 378406, 2006.

"Complexidade social e soberania popular: uma tensão constitutiva na teoria democrática". Teoria e Pesquisa, vol. 16, n 1, p. 61-95, 2007.

FISCHER, F. Democracy and expertise: reorienting policy inquiry. Oxford; New York: Oxford University Press, 2009.

FISHKIN, J. S. When the people speak: deliberative democracy and public consultation. Oxford: Oxford University Press. 2009. 
FONSECA, I. F. Participação como método de governo: experiências transcalares no Rio Grande do Sul, Brasil, e na Toscana, Itália. Brasília: Instituto de Pesquisa Econômica Aplicada, 2019. Disponível em:

<http://www.ipea.gov.br/portal/images/stories/PDFs/livros/livros/190212_participacao_como_meto do_de_governo.pdf $>$. Acesso em: nov. 2019.

GoldFrank, B. "Participation, distribution, and the left: the return of PB in Rio Grande do Sul". Painel A New Critical Juncture? Changing Patterns of Representation and Regime Politics in Contemporary Latin America. Kellogg Institute, University of Notre Dame, April 24-26, 2014.

GoldFrank, B.; SCHNEIDER, A. "Competitive institution building: the PT and participatory budgeting in Rio Grande do Sul". Latin American Politics and Society, vol. 48, n³, p. 1-31, 2006.

Goodin, R. E. "Sequencing deliberative moments". Acta Politica, vol. 40, n² 2, p. 182-196, 2005.

Goodin, R. E.; DRYZEK, J. S. "Deliberative impacts: the macro-political uptake of mini-publics". Politics \& Society, vol. 34, n², p. 219-244, 2006.

GRINDLE, M. S. "Good enough governance: poverty reduction and reform in developing countries". Governance, vol. 17, n 4, p. 525-548, 2004.

$\overline{574,2007 .}$

. "Good enough governance revisited". Development Policy Review, vol. 25, n 5, p. 533-

GRS. Governo do Estado do Rio Grande do Sul. Orçamento Participativo do Rio Grande do Sul Brasil: quatro anos de gestão democrática (1999/2002). Porto Alegre: Governo do Estado do Rio Grande do Sul, 2002.

. Sistema estadual de participação: construção e desafios. Porto Alegre: Governo do Estado do Rio Grande do Sul, 2014a.

. Gabinete digital - Democracia em rede (balanço 2011-2014). Porto Alegre: Governo do Estado do Rio Grande do Sul, 2014b.

Guimarães, M.; MARTins, T. C. "Participação social e desenvolvimento: conselhos regionais no Chile e no Rio Grande do Sul". Revista Brasileira de Gestão e Desenvolvimento Regional, vol. 9, n 3, p. 130-153, 2013.

HABERMAS, J. Between facts and norms: contributions to a discourse theory of law and democracy. Studies in Contemporary German Social Thought. Cambridge: MIT Press, 1992.

HENDRIKS, C. M. "Integrated deliberation: reconciling civil society's dual role in deliberative democracy". Political Studies, vol. 54, n 3, p. 486-508, 2006.

LAvalle, A. G.; Houtzager, P. P.; CASTello, G. "Democracia, pluralização da representação e sociedade civil". Lua Nova, vol. 67, p. 49-103, 2006.

LÜCHMANN, L. H. "A representação no interior das experiências de participação". Lua Nova, vol. 70, p. 139-170, 2007.

MAHONEY, J. "The logic of process tracing tests in the social sciences". Sociological Methods \& Research, vol. 41, n 4, p. 570-597, 2012.

MANSBRIDGE, J. Everyday talk in the deliberative system. In: MACEDO, S. (ed.). Deliberative politics: essays on democracy and disagreement. Oxford: Oxford University Press, p. 211-242, 1999. $528,2003$.

"Rethinking representation". American Political Science Review, vol. 97, n 4, p. 515-

. "Clarifying the concept of representation". American Political Science Review, vol. 105, $\mathrm{n}^{\circ} 3$, p. 621-630, 2011.

MANSBRIDGE, J., et al. "The place of self-interest and the role of power in deliberative democracy". Journal of Political Philosophy, vol. 18, n 1, p. 64-100, 2010. 
. A systemic approach to deliberative democracy. In: PARKInSON, J.; MANSBRIDGE, J. (eds.). Deliberative systems: deliberative democracy at the large scale. Cambridge: Cambridge University Press, p. 1-26, 2012.

MARQUES, E. C. "Redes sociais e poder no Estado brasileiro: aprendizados a partir das políticas urbanas". Revista Brasileira de Ciências Sociais, vol. 21, nº 60, p. 15-41, 2006.

Mellon, J.; Peixoto, T.; Sjoberg, F. M. "Does online voting change the outcome? Evidence from a multi-mode public policy referendum". Electoral Studies, vol. 47, p. 13-24, 2017.

MENDONÇA, R. F. "Mitigating systemic dangers: the role of connectivity inducers in a deliberative system". Critical Policy Studies, vol. 10, n², p. 171-190, 2016.

MIGDAL, J. S. State in society: studying how states and societies transform and constitute one another. Cambridge: Cambridge University Press, 2004.

MohAN, G.; STOKKE, K. "Participatory development and empowerment: the dangers of localism". Third World Quarterly, vol. 21, n² 2, p. 247-268, 2000.

Mouffe, C. "Deliberative democracy or agonistic pluralism?". Social Research, vol. 66, n 3, p. 745758, 1999.

. Agonistics: thinking the world politically. London: Verso Books, 2013.

PAteman, C. Participation and democratic theory. Cambridge: Cambridge University Press, 1970.

"Participatory democracy revisited". Perspectives on Politics, vol. 10, n 1, p. 7-19, 2012.

Peixoto, T.; Sjoberg, F.; Mellon, J. "A get-out-the-vote experiment on the world's largest participatory budgeting vote in Brazil". British Journal of Political Science, p. 1-9, 2017.

PIRES, R. R. (ed.). Efetividade das instituições participativas no Brasil: estratégias de avaliação. Brasília: Ipea, 2011.

PIReS, R. R.; VAZ, A. Participação social como método de governo: um mapeamento das "interfaces socioestatais" nos programas federais. Brasília: Funag, 2012.

PURCELL, M. Recapturing democracy: neoliberalization and the struggle for alternative urban futures. New York: Routledge, 2008.

SABATIER, P.; Weible, C. The advocacy coalition framework: innovations and clarifications. In: Sabatier, P. (ed.). Theories of the policy process. New York: Westview Press, p. 189-220, 2007.

SANTISO, C. "Good governance and aid effectiveness: the World Bank and conditionality". The Georgetown Public Policy Review, vol. 7, n 1, p. 1-22, 2001.

SANTOS, B. S. A reinvenção solidária e participativa do Estado. In: BRESSER-PEREIRA, L. C.; WiLHEIM, J.; SolA, L. (eds.). Sociedade e Estado em transformação. São Paulo: Unesp, p. 243-271, 1999.

Santos, B. S.; Avritzer, L. Para ampliar o cânone democrático. In: SAntos, B. S. (ed.). Democratizar a democracia: os caminhos da democracia participativa. Rio de Janeiro: Civilização Brasileira, p. 39-82, 2002.

SANYAL, B. "Planning as anticipation of resistance". Planning Theory, vol. 4, n 3, p. 225-245, 2005.

SAWARD, M. "The representative claim". Contemporary Political Theory, vol. 5, n 3, p. 297-318, 2006.

Schumpeter, J. A. Capitalismo, socialismo e democracia. Rio de Janeiro: Fundo de Cultura, 1961.

Silva, M. K.; OliveirA, G. L. "A face oculta (da) dos movimentos sociais: trânsito institucional e intersecção Estado-Movimento - uma análise do movimento de economia solidária no Rio Grande do Sul". Sociologias, vol. 13, n²8, p. 86-124, 2011.

Silva, R. S.; Gugliano, A. A. "Rio Grande do Sul, o estado da participação popular: a trajetória da participação no orçamento estadual". XI Congresso Nacional y IV Congresso Internacional sobre Democracia "Entre el malestar y la inovación". Rosário, Argentina, 8-11 de setembro de 2014. 
SINTOMER, Y., et al. "Learning from the South: participatory budgeting worldwide - An invitation to global cooperation". Dialog Global, vol. 25, p. 85, 2010.

SовоTTKA, E. A.; STRECK, D. R. "When local participatory budgeting turns into a participatory system. Challenges of expanding a local democratic experience". International Journal of Action Research, vol. 10, p. 156-183, 2014.

SouzA, C. H.; LimA, P. F.; TeixeirA, A. C. "Conselhos e conferências nacionais: entre a participação e a representação". Argumentum, vol. 4, n 1, p. 152-172, 2012.

SPADA, P., et al. "Effects of the internet on participation: study of a public policy referendum in Brazil". Policy Research Working Paper (World Bank), 7204, 2015.

URBINATI, N.; WARREN, M. E. "The concept of representation in contemporary democratic theory". Annual Review of Political Science, vol. 11, n 1, p. 387-412, 2008.

WAMPLER, B.; AVRITZER, L. "The spread of participatory democracy in Brazil: from radical democracy to participatory good government". Journal of Latin American Urban Studies, vol. 7, p. 737-752, 2006.

YIN, R. K. Case study research: design and methods. London: Sage Publications, 2014.

\begin{abstract}
Resilience, scale and participation in right-wing governments: an analysis of the Popular Consultation in Rio Grande do Sul (1998 - 2018)

The environment around Brazilian participatory institutions is marked by a certain stagnation, based on its historical ties to left-wing parties. After the 2018 elections, it became necessary to pay attention to active experiences in conservative governments. This paper analyzes a supralocal experience, institutionalized by a right-wing government, that has a trajectory spanning 20 years: the Popular Consultation, in Rio Grande do Sul. The theoretical basis of this work discusses the scaling-up and the institutionalization of participation. The methodology is qualitative, with emphasis on process tracing. The results show that the scaling-up was insufficient to ensure a broad change in the political system. However, Popular Consultation is an innovative way to promote supra-local participation and deliberation, based on a good enough governance perspective. Institutionalization is fundamental to explaining its resilience to changes of government. Finally, this case signals that if the participatory institution shows results in terms of the efficiency of public management and does not have the ambition to change the pre-established status quo, the participation mechanism can be tolerated and encouraged in conservative governments.
\end{abstract}

Keywords: scaling-up; institutionalization; Rio Grande do Sul; Popular Consultation; deliberative systems

\title{
Resumen
}

Resiliencia, escala y participación en gobiernos de derecha: un análisis de la Consulta Popular en Rio Grande do Sul (1998 - 2018)

El escenario en torno a las instituciones participativas brasileñas está marcado por cierto estancamiento, tomando en cuenta vínculos históricos con partidos de izquierda. En la coyuntura posterior a las elecciones de 2018 , se hace necesario volver la mirada a las experiencias activas en gobiernos conservadores. En esta línea, este artículo analiza una experiencia supralocal institucionalizada por un gobierno de derecha y que posee más de veinte años de historia: la Consulta Popular, en Rio Grande do Sul. El referencial teórico discute el salto de escala y la institucionalización de la participación, la metodología utilizada fue cualitativa, con énfasis en la técnica de process tracing. Los resultados muestran que el aumento de escala fue insuficiente para garantizar una transformación amplia del sistema político. Sin embargo, la Consulta presenta una forma innovadora de promover la participación y la deliberación a escala supralocal, desde la perspectiva de una gobernanza suficientemente buena. La institucionalización fue fundamental para explicar su resiliencia en relación a los cambios de gobierno. Por último, el caso apunta que, si la institución participativa muestra resultados en términos de eficiencia en la gestión pública y no tiene la ambición de alterar el statu 
quo preestablecido, la participación puede ser tolerada e incentivada en gobiernos de derecha.

Palabras clave: salto de escala; institucionalización; Rio Grande do Sul; Consulta Popular; sistemas deliberativos

\section{Résumé}

Résilience, échelle et participation dans les gouvernements de droite: une analyse de la Consultation Populaire dans le Rio Grande do Sul (1998 - 2018)

Le scénario autour des institutions participatives brésiliennes est marqué par une certaine stagnation, eu égard aux liens historiques établis avec les partis de gauche. Après les élections de 2018, il est nécessaire de revenir sur les expériences actives des gouvernements conservateurs. Cet article analyse une expérience supralocale institutionnalisée par un gouvernement de droite et qui a plus de vingt ans d'histoire: la Consultation populaire, dans le Rio Grande do Sul. Le référentiel théorique discute le changement d'échelle et l'institutionnalisation de la participation. La méthodologie était qualitative et mettait l'accent sur la technique de process tracing. Les résultats montrent que le saut d'échelle était insuffisant pour assurer une vaste transformation du système politique. Cependant, la Consultation présente une forme innovante de promouvoir la participation et la délibération au niveau supralocale, dans la perspective d'une gouvernance suffisamment bonne. L'institutionnalisation était fondamentale pour expliquer sa résilience face aux changements de gouvernement. Enfin, l'affaire souligne que si une institution participative obtient des résultats en termes d'efficacité dans la gestion publique et qu'elle n'a pas l'ambition de changer le status quo préétabli, sa participation peut être tolérée et encouragée dans les gouvernements de droite.

Mots-clés: saut d'échelle; institutionnalisation; Rio Grande do Sul; Consultation Populaire; systèmes délibératifs

Artigo submetido à publicação em 10 de abril de 2018. Artigo ressubmetido à publicação em 15 de janeiro de 2019.

Versão final aprovada em 8 de agosto de 2019.

Opinião Pública adota a licença Creative Commons CC-BY. 